\title{
A coupled hydrological-hydraulic flash flood forecasting system for Kuala Lumpur's Stormwater Management and Road Tunnel (SMART)
}

\author{
$\underline{\text { WJ Cohen }}^{\mathrm{a}}$, P Pokhrel ${ }^{\mathrm{a}}$, D Fuller ${ }^{\mathrm{a}}$ and JM Peterson ${ }^{\mathrm{a}}$ \\ ${ }^{a}$ Entura/Hydro Tasmania \\ Email: Bill.Cohen@entura.com.au
}

\begin{abstract}
Kuala Lumpur's Storm Management and Road Tunnel (SMART) is the longest multi-purpose tunnel in the world. The tunnel serves two purposes: to relieve key locations in the city from frequent flash flooding, and to serve as a section of highway through the city to relieve traffic congestion. During flood operation, a series of gates, pumps, and storage reservoirs operate to divert river discharge into the tunnel, bypassing the city centre.
\end{abstract}

A critical component of tunnel operation is effective forecasting of flash flooding events in the city and its upstream catchment. The region is prone to flash flooding, so there is usually very little warning of events that require tunnel operation. The flood detection system is a loosely coupled hydrological/hydraulic model of the catchment, river channels, and tunnel. It acquires real-time information from a SCADA (Supervisory Control and Data Acquisition) system, which in turn retrieves data from instrumentation in the field. This includes catchment rainfall (from a dense raingauge network), streamflow (using rated stage-discharge recorders and Doppler current meters), gate position, pump operation and equipment failure.

The hydrological model is a semi-distributed conceptual rainfall-runoff model, which simulates catchment soil moisture states (storages) over time. The model is executed in two modes: (1) warmup mode: which initializes the model state variables up to the current time using the latest observed data and (2) forecast mode: which generates forecasts of streamflow at key points in the river network 2 hours into the future. The inflow hydrographs generated by the hydrological model are fed into the one-dimensional hydraulic model, which represents the river channels, storage reservoirs, gates and pumps, and tunnel decks. A series of operating rules for the tunnel infrastructure are programmed into the model, to allow it to adequately forecast flood levels when the tunnel is operated accordingly. The hydraulic model's major outputs are forecasts of river height at key locations of the catchments.

The coupled model is designed to run every 5 minutes. The forecast system assumes that there is persistence in the rainfall over a short interval of time and uses a simple algorithm to project rainfall observed in the last interval 30 minutes into the future. In the current form the forecast system does not use Numerical Weather Prediction (NWP) model rainfall forecasts since as these forecasts are not available at the fine temporal resolution or frequency required. Furthermore, at very short lead times - less than 2 hours - the skill of streamflow forecasts are predominantly influenced by the persistence (or memory) of the catchment (simulated by model state variables).

Keywords: Flash flooding, flood-forecasting, rainfall-runoff modelling, hydraulic modelling, urban flooding 
Cohen et al., A coupled hydrological-hydraulic flash flood forecasting system for Kuala Lumpur's Stormwater Management and Road Tunnel (SMART)

\section{INTRODUCTION}

Kuala Lumpur, the capital city of Malaysia, is a major metropolitan city in South East Asia. It is situated in the valley of the Klang River (Sungai Klang: Sungai is the Malay word for River and is abbreviated as Sg), where many tributaries converge. The city's name (Malay for 'muddy confluence') comes from the confluence of the Sg Klang and the Sg Gombok (Figure 1), the location of the city's centre.

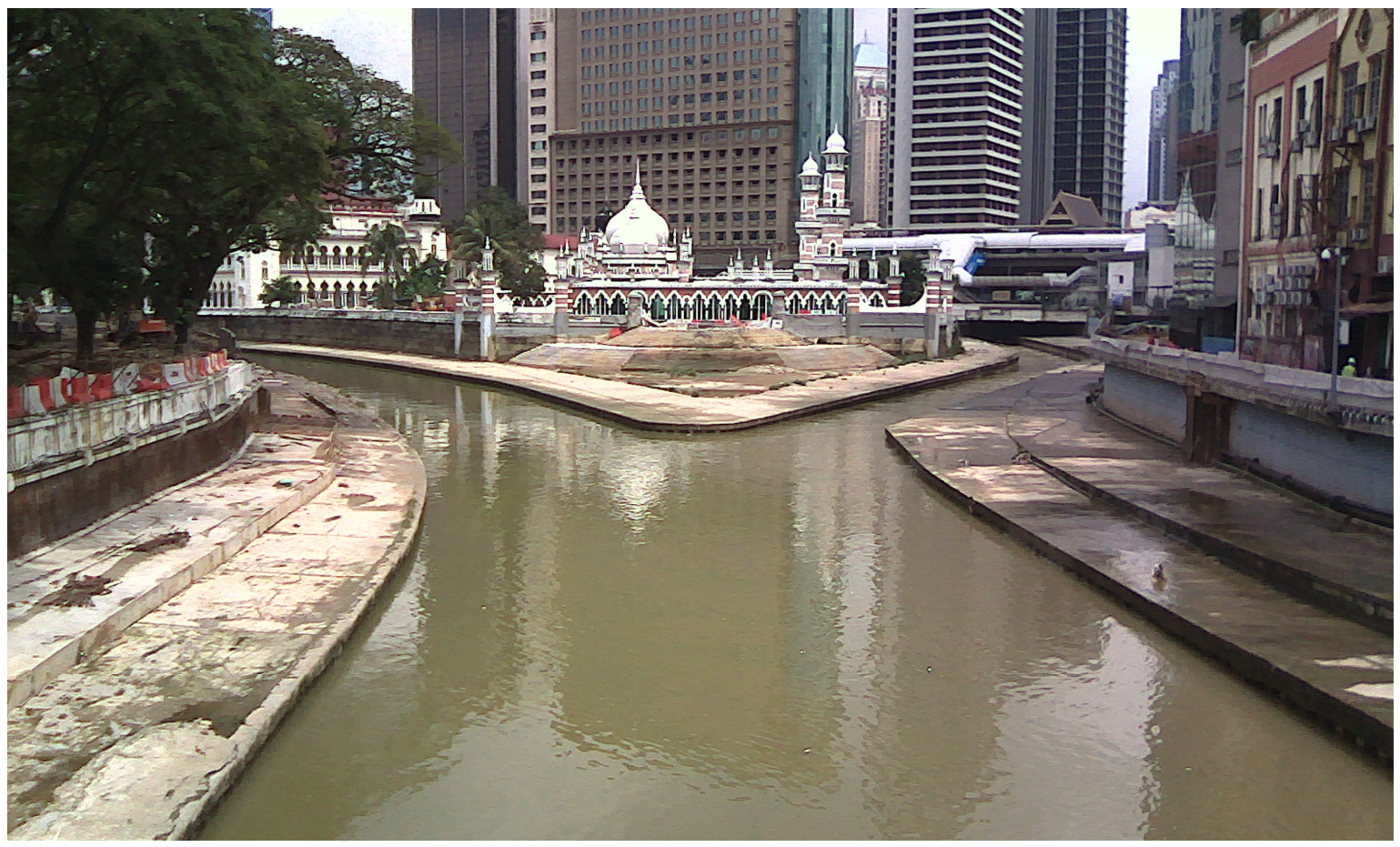

Figure 1. Confluence of the Sg Klang (right) and the Sg Gombok (left); the Sultan Abdul Samad Jamek Mosque is in the background. Tun Perak Bridge can be seen towards the top right.

The city has historically been prone to significant and frequent flooding, which has the usual negative impacts to the citizens' welfare and the nation's economy associated with such events. The Jamek Mosque (Figure 1) is situated at the confluence of the Sg Gombok and Sg Klang and is therefore is subject to a major risk of flooding.

In the early 2000s, the Government of Malaysia commissioned the construction of the Stormwater Management and Road Tunnel, referred to as the SMART Tunnel, in order to mitigate flooding in the city. A secondary purpose of the tunnel was to alleviate traffic congestion in the city, so a section of the tunnel also houses a highway. This section is divided into three decks: the lower deck is dedicated for stormwater only, while the upper two decks contain the highway and can be evacuated during significant flood events to increase the capacity of flood mitigation.

A map of the rivers and city is given in Figure 2. Key locations in the tunnel network are:

- Diversion structure/control centre/holding pond: this location is immediately downstream of the $\mathrm{Sg}$ Klang/Sg Ampang confluence, with a total catchment area of approximately $83 \mathrm{~km}^{2}$, excluding the catchment upstream of the Klang Gates Dam - releases from this dam are regulated

- Tun Perak Bridge: a major objective of the tunnel is to reduce flooding at this site; the bridge is a major hydraulic constriction, and contributes to flooding immediately upstream

- Tunnel outlet/attenuation pond: after tunnel operation, water is pumped out of this pond into the $\mathrm{Sg}$ Kerayong from where it will naturally flow back into the Sg Klang downstream of the city

During flood operation, diversion gates stop discharge down the Sg Klang and offtake gates open to divert this flow into the holding pond. The tunnel intake is located within the holding pond, and is fed through a glory hole spillway. Several pumps are located along the tunnel to drain it after use. The tunnel discharges 
Cohen et al., A coupled hydrological-hydraulic flash flood forecasting system for Kuala Lumpur's Stormwater Management and Road Tunnel (SMART)

into a larger attenuation pond downstream of the city; water is then regulated from this pond into the $\mathrm{Sg}$ Kerayong, which then flows back into the Sg Klang having been diverted away from the city.

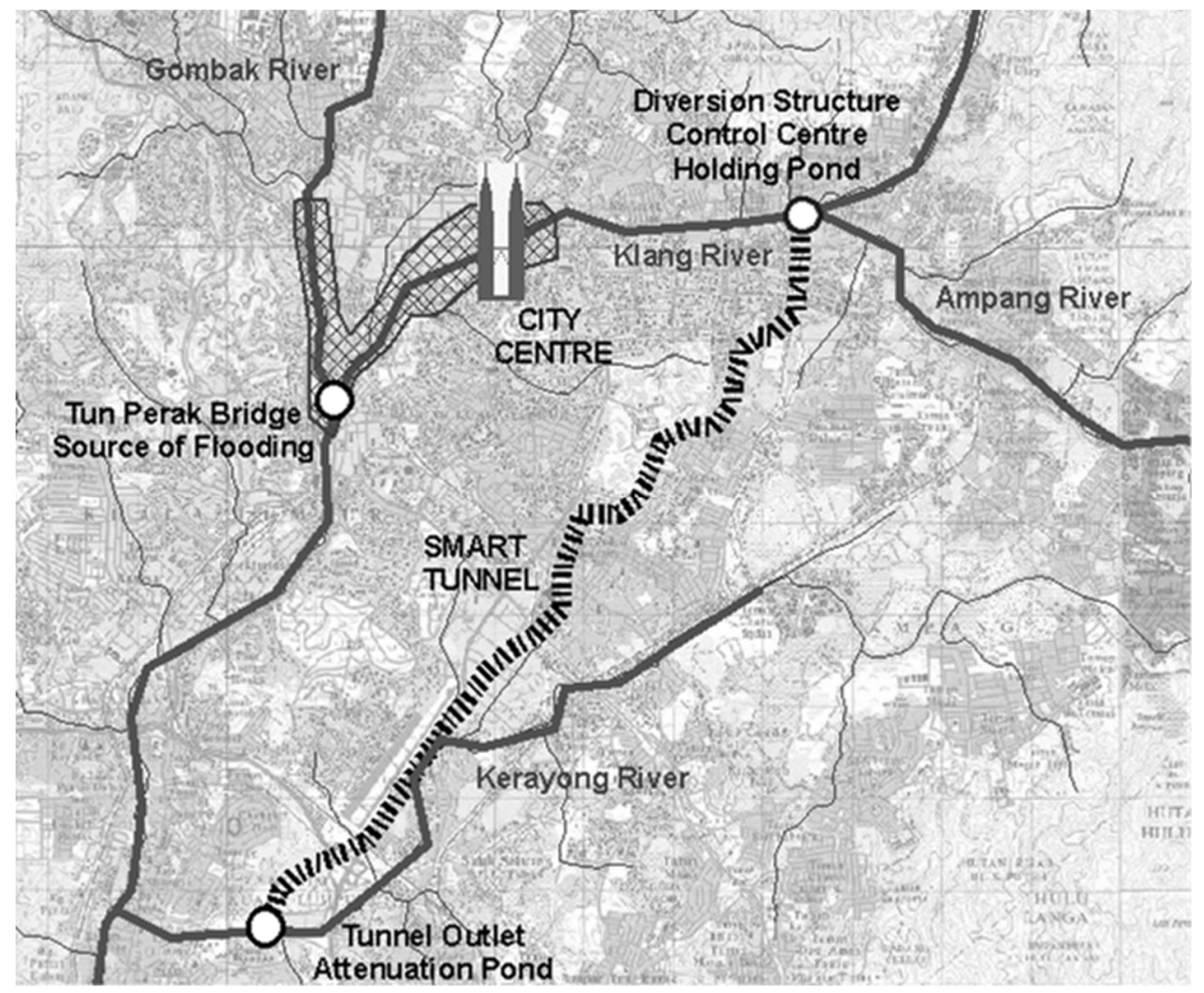

Figure 2. Map of the rivers and tunnel in Kuala Lumpur.

A critical component to tunnel operation is the flood detection system (FDS), a loosely coupled hydrological/hydraulic model (featuring loose coupling; ie data feeds in one direction from the hydrological model to the hydraulic model) that forecasts flash floods generated from convective storms crossing the Malay Peninsula. The system is comprised of the following components:

- A network of hydrometric sensors (rainfall, river level/velocity, storage pond levels, gate openings/operating failures and pump operation/operating failures), cameras and controllers linked to a central SCADA system (SCADA: Supervisory Control and Data Acquisition - a computer control system managing field-based instrumentation and infrastructure, telemetry, data storage and interfaces)

- A hydrometric database which includes rating tables for flow monitoring sites and an operating system service that synchronises data between the database and the SCADA system

- A hydrological model of the city's catchment areas

- A hydraulic model of the tunnel as well as the city's river channels

- Data transfer and visualisation processes that synchronise data between the components and publish forecasts of catchment-wide rainfall, river discharge into the system, and flood levels at a key location in the city

- A user interface, driven through the SCADA system, which displays forecast information. Three timeseries plots are prioritised:

- 'Target' catchment average rainfall (for the catchment area upstream of the diversion structure) computed from observed rainfall

- Inflow to the diversion structure (computed in the hydrological model)

- $\quad$ River levels at Tun Perak Bridge (computed in the hydraulic model)

The hydrological model and hydraulic model are discussed in more detail in Sections 3 and 4, respectively.

\section{TUNNEL OPERATION MODES}

The SMART tunnel operates in several modes, which are triggered by different flood conditions. Major modes are illustrated in Figure 3. 
Cohen et al., A coupled hydrological-hydraulic flash flood forecasting system for Kuala Lumpur's Stormwater Management and Road Tunnel (SMART)

- Mode 1 (no flooding or water in the tunnel) - this is for low flow conditions, the default system configuration

- Mode 2 (water discharged through the lower tunnel deck) - triggered when inflow to the confluence exceeds $70 \mathrm{~m}^{3} / \mathrm{s}$

- Mode 3 (significant flooding where the highway decks are evacuated of traffic and are used to divert more flood water) - triggered when inflow to the confluence exceeds $150 \mathrm{~m}^{3} / \mathrm{s}$

- Mode 2b (flooding in the Sg Gombok) - this mode is triggered when there is significant flooding in the Sg Gombok, which can backwater up the Sg Klang into the city: even though discharges at the tunnel intake may be low, the tunnel may be operated to alleviate further flooding

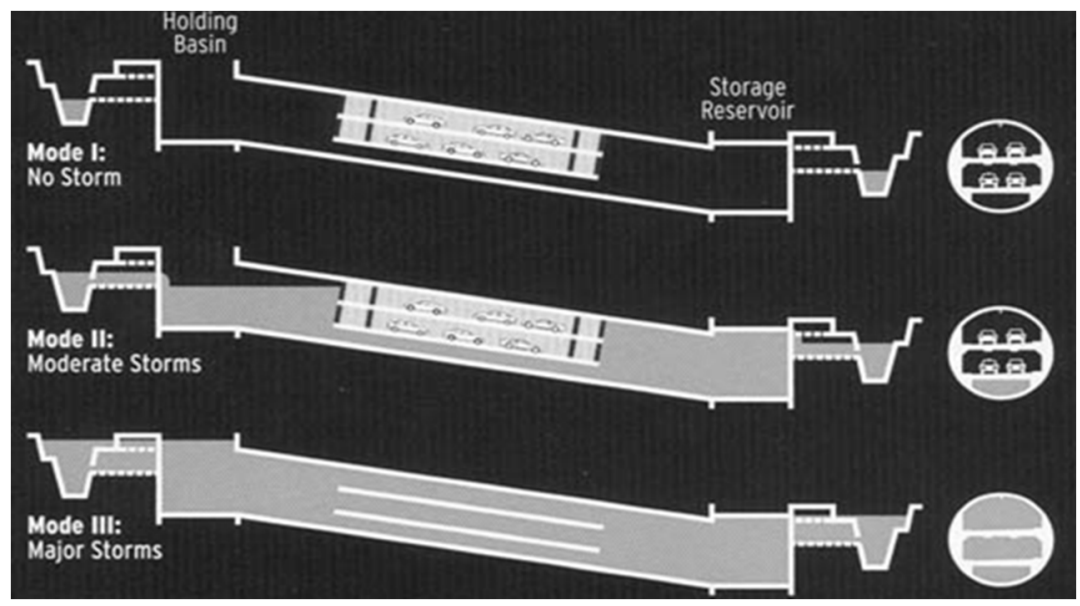

Figure 3. Major tunnel operating modes

During planning, it was anticipated that Mode 2 events would occur eight-ten times per year and Mode 3 events would occur approximately once per year or every two years (Abdullah 2004). Operating records indicate that these events occur at a considerably higher frequency; since tunnel operation has commenced in 2007 there have been 212 Mode 2 events and 82 Mode 3 events (JPS Malaysia 2017); approximately 21 per year and eight per year respectively. This discrepancy may be due to several reasons. One suggestion is a difference between the flood frequency adopted at the time of design, and what would be an estimate of flood frequency based on the most recent data available. This in turn may be attributed to changes in the catchment and channel (eg channel lining activities) or possibly the flood frequency analysis at design time may have been based off a period of record that is not representative of conditions in recent years.

As well as these modes of operation, the tunnel has numerous override rules that are triggered by additional conditions. These are generally to protect the SMART tunnel infrastructure from damage should flooding exceed the tunnel capacity or in the event of gate failures.

\section{HYDROLOGICAL COMPONENT}

The primary purpose of the hydrological modelling component in the SMART FDS is to provide inflow hydrographs to the hydraulic component (described in Section 4). The hydrograph representing inflow to the diversion structure is of primary importance, and so is displayed on the main screen of the FDS interface. The hydrological model used in the FDS is a semi-distributed rainfall-runoff model covering $280 \mathrm{~km}^{2}$ (Hydro Tasmania Consulting 2008). This includes $83 \mathrm{~km}^{2}$ of catchment contributing to inflow at the diversion structure (Figure 2). A further $320 \mathrm{~km}^{2}$ of contributing catchment is not modelled as it is either regulated by dams or does not have significant contributions to storm runoff. In these instances, runoff is accounted for by observed streamflow sites or using assumptions regarding dam baseflow releases.

Soil moisture accounting is completed using an adaption of the Australian Water Balance Model (AWBM; Boughton 2004). The catchment area is divided into approximately 100 subcatchments. Rainfall timeseries data is collected from a network of 22 rain gauges in the region. Rainfall is distributed to subcatchment centroids using inverse-distance weightings; the same technique is applied for infilling missing rainfall records at the raingauge locations prior to the distribution to subcatchments. Runoff from the subcatchments is then transferred through river channels using an adaption of Laurenson's non-linear channel routing method. 
Cohen et al., A coupled hydrological-hydraulic flash flood forecasting system for Kuala Lumpur's Stormwater Management and Road Tunnel (SMART)

The model is run on a 5 minute timestep, in order to capture the peaks of a very responsive catchment. Large storm events can frequently cause discharge at the diversion structure to rise from a baseflow of $5 \mathrm{~m}^{3} / \mathrm{s}$ to over $100 \mathrm{~m}^{3} / \mathrm{s}$ and recede again within a 2 hour period. The model simulates a period starting 48 hours prior to the current time ${ }^{1}$ to 2 hours into the future. Accordingly, every time the model runs it operates in two modes $^{2}$ : warmup and forecast. The model starts running in warmup mode, with all observed data available. The soil moisture accounting and routing algorithms convert the observed rainfall into streamflow. Where discharge data is available, modelled streamflow is auto-corrected to measured streamflow using an amplitude correction method (Hydro Tasmania Consulting 2008) as follows:

- For time periods where measured discharge data is available, it is used in preference to modelled discharge; a correction factor (the difference between measured and modelled) is recorded at each timestep

- In periods with no measured data, the correction factor is applied to the modelled data. The correction factor is reduced by a decay factor of 0.99 for each timestep without measured data

When the model time reaches the current ('now') time, the model switches to its forecast mode. No observed rainfall data is available, so a simple forecasting algorithm has been applied: future rainfalls are estimated by linearly decaying the latest measured rainfall to zero 30 minutes into the future. This approach was selected based on the decay of historical rainfall patterns and the assumption of rainfall persistence (Hydro Tasmania Consulting 2008); however, it does lead to errors in both temporal and spatial patterns of rainfall in the forecast period. The accuracy of forecasts could be improved in future with rain radar or other frequently updated rainfall nowcasting systems, should they become available.

The system state (ie state of the catchment) is stored in a 'hotstart' file, which means that the model only needs to run computations for time-steps where there is new observed data since the last model execution. The model is designed to complete a full cycle (including the hydraulic model run, see chapter 4) within a 5 minute period. This update frequency is due to the rapid rise of floodwaters in the catchment.

\section{HYDRAULIC COMPONENT}

The hydraulic modelling component used in the SMART forecast system is a 1-dimensional hydraulic model using the DHI Mike 11 software package. The model has been adapted from a model of the Sg Klang originally developed by a local consultancy based in Kuala Lumpur, Dr. Nik \& Associates Sdn. Bhd. A major extension of this original model is the inclusion of a representation of the tunnel operating rules, including conditions that trigger operation of gates and pumps, gate failure rules, and override rules. A thorough description of the hydraulic model is given by Ludlow (2008).

The model consists primarily of two main branches, both originating at the diversion structure and both ending at the confluence of the Sg Kerayong and Sg Klang, downstream of the city (towards the lower left of Figure 2). One of the branches represents the Sg Klang channel, together with diversion gates and other flow restrictions. The other branch represents the offtake gates (from the Sg Klang into the holding pond), the tunnel (with many series of gates and pumps), the tunnel outlet/attenuation pond, and the Sg Kerayong section between the attenuation pond and the Sg Klang confluence.

It operates similarly to the hydrological model, in two modes: warmup and forecast. Inflow hydrographs (including in the forecast period) are picked up from the hydrological model. In warmup mode, all system settings are taken from observed readings. When the model switches to forecast mode, the model follows the tunnel operating rules that have been programmed into it. Therefore, the accuracy of flood level forecasts is dependent on the tunnel being managed according to its specified rules of operation.

\section{FORECAST PERFORMANCE}

A review of model outputs has shown that the system is generally able to predict flood hydrographs to a reasonable degree of accuracy. Forecasts with longer lead times generally under-predict the eventual peak; generally this is due to the forecast being issued prior to the majority of rainfall occurring. This highlights the limitations of the rainfall forecasting algorithm; the system could benefit from a more sophisticated rainfall forecasting or 'nowcasting' system.

\footnotetext{
1 ie the point in time that the model run itself is executed

${ }^{2}$ Model operation mode is unrelated to tunnel operation mode described in Section 2
} 
Cohen et al., A coupled hydrological-hydraulic flash flood forecasting system for Kuala Lumpur's Stormwater Management and Road Tunnel (SMART)

\section{MODEL CALIBRATION AND VALIDATION}

Generally, hydrometric records in the system are available from 2006/2007 onwards, with the SMART system commencing operation in 2007. Manual hydrological model calibrations have been completed in 2008, 2009, 2010, and 2016. Calibration has been performed at a number of reporting points in the model, with a focus on the diversion structure and at four gauging stations upstream of it (two in the Sg Ampang and two in the Sg Klang). The largest event on record occurred in March 2012, where the peak inflow to the diversion structure was estimated to be $\sim 450 \mathrm{~m}^{3} / \mathrm{s}$ (Entura 2016); there is considerable uncertainty around this estimate however, due to water breaking the river channel banks and levels exceeding rating curves.।

The hydraulic model is currently validated against a large event every three months. The model generally performs well, however it is expected that planned developments of river channels will require a model update and possible recalibration in the near future.

\section{CURRENT ISSUES}

The SMART FDS is a complex flood forecasting system, which relies on a large network of observed data. It requires frequent changes to ensure that it adequately reflects the physical system it represents (ie the catchment/channels/SMART tunnel). Kuala Lumpur is a large city, which is also undergoing significant further development. Developments in river channels can change their discharge characteristics, and other developments can affect the placement of sensors in the hydrometric network. The model requires frequent updates to reflect these changes, but also needs to record the history of these changes in order for it to be calibrated against historic flood events.

\subsection{Rubbish in the catchment}

During flood events, considerable quantities of rubbish can be picked up by floodwaters and end up in the holding pond. A system of trash racks has been installed at critical locations throughout the channels; however this too can present problems. Rubbish pushed up against the trash racks can affect the discharge characteristics of these locations, which in turn affect the estimation of discharge. In addition, rubbish can clog or damage sensors in the system, leading to inaccurate readings.

\subsection{Communication of uncertainty}

There is inherent uncertainty in the forecast system, as there is with any modelling system. While the system generally provides suitably accurate forecasts, events can occur during a flood that impact this accuracy, and warrant explanation. A description of sources of uncertainty affecting the FDS is given below, according to two types of uncertainty defined by Ball et al. (2016):

- Aleatory uncertainty: due to natural variability and randomness in a complex system

- Epistemic uncertainty: limits of the information that is available

Different components in the forecasting system are subject to different sources of uncertainty: Table 1 captures a subset of these.

Table 1. Sources of uncertainty in the components of the forecasting system

\begin{tabular}{|l|l|l|}
\hline Component & Aleatory uncertainty & Epistemic uncertainty \\
\hline Data collection & $\begin{array}{l}\text { Rubbish damaging sensors during } \\
\text { a flood } \\
\text { Network errors causing data } \\
\text { latency }\end{array}$ & $\begin{array}{l}\text { Limits of the raingauge network in } \\
\text { representing the catchment } \\
\text { Limits in stage-discharge and Doppler- } \\
\text { current meter ratings }\end{array}$ \\
\hline Hydrological modelling & $\begin{array}{l}\text { Lack of forecast rainfall and the } \\
\text { unknown pattern of future rainfall } \\
\text { in the event }\end{array}$ & $\begin{array}{l}\text { Suitability of the model to represent the } \\
\text { catchment; suitability of the events } \\
\text { selected for model calibration to } \\
\text { represent a given event }\end{array}$ \\
\hline Hydraulic modelling & $\begin{array}{l}\text { Gate operating failures mean that } \\
\text { gate operation is not as forecast } \\
\text { in turn meaning flood levels may } \\
\text { exceed those forecast }\end{array}$ & $\begin{array}{l}\text { Suitability of the model to represent the } \\
\text { tunnel/channel network } \\
\text { Developments in the city over time }\end{array}$ \\
\hline
\end{tabular}


Cohen et al., A coupled hydrological-hydraulic flash flood forecasting system for Kuala Lumpur's Stormwater Management and Road Tunnel (SMART)

Communicating these differing uncertainties to end users is challenging. Given the short design cycle time of 5 minutes, there is little time to consider probabilistic forecasting as an approach to representing uncertainty in the forecast. In practise, qualitative descriptions of differences between observed and modelled hydrographs serve best. Nevertheless, one method of addressing this issue is currently under consideration the implementation of a 'scenario system'. This would allow SMART operators to manually configure an event, together with selected tunnel operation, to determine what the likely flood outcome would be under differing scenarios.

A scenario system would allow for several workflows that could assist in SMART operation. One of these is during a forecast, to determine the impact of operating or not operating the tunnel under given forecast rainfalls. Additionally, forecast rainfalls could be reduced or increased to assess the likelihood of a mode change (ie the likely increase of a Mode 1 event to a Mode 2 or Mode 3).

Another benefit of the scenario system would be to assess different operation on historical events, eg to assess the impact of gate failure on flood levels. Other scenarios could be to assess the impacts of planned changes in the city (eg river channel works, other diversions) on historical events to determine the impact of infrastructure or landuse change on city flooding.

\section{CONCLUSION AND FURTHER WORK}

The SMART FDS is an effective system that adds vital warning time to flood events affecting Kuala Lumpur and requiring tunnel operation.

Various approaches are under consideration for the improvement of forecasts and estimating forecast uncertainty, such as the introduction of rain-radar and the use of a scenario system.

While the tunnel has been successfully mitigating floods in the city since 2007 , the operating costs can be high. This is largely due to operating pumps and cleaning the tunnel and associated infrastructure. It is planned to review flood events in the tunnel's history in order to optimise its operation. This should allow for reducing operating costs while still mitigating floods in the city.

An update to the flood frequency at the diversion structure is also planned for the near future.

\section{ACKNOWLEDGEMENTS}

The authors wish to acknowledge Ir. Amiruddin bin Alaldin (Jabatan Pengairan dan Saliran/Department of Irrigation and Drainage Malaysia) for his support in granting the permission to present the outcome of the project.

\section{REFERENCES}

Abdullah, K. (2004). Stormwater Management and Road Tunnel (SMART) a lateral approach to flood mitigation works. In International Conference on Bridge Engineering and Hydraulic Structures. Selangor, Malaysia, pp. 59-79.

Ball, J. et al. (2016). Australian Rainfall and Runoff: A Guide to Flood Estimation, Canberra, ACT.

Boughton, W. (2004). The Australian water balance model. Environmental Modelling \& Software, 19(10), pp.943-956.

Entura (2016). SMART FDS Operation and Maintenance: Hydrological Model Calibration Report, Hobart, TAS.

Hydro Tasmania Consulting (2008). Stormwater Management and Road Tunnel (SMART) Project: Functional Specification - FDS Modelling System (unpublished report), Hobart, TAS.

JPS Malaysia (2017). SMART Control Centre Official Website. Available at: http://state.water.gov.my/scc/index.php/en/services/statistics [Accessed September 30, 2017 ].

Ludlow, C. (2008). Hydraulic Modelling of the Kuala Lumpur Stormwater Management and Road Tunnel (SMART) for a Real-time Flood Detection System. In 9th National Conference on Hydraulics in Water Engineering: Hydraulics. Barton ACT: Engineers Australia, pp. 9 - 27. 